\title{
Myeloperoxidase gene sequence variations are associated with low-density-lipoprotein characteristics
}

\author{
Guillaume Dolley $\cdot$ Benoit Lamarche $\cdot$ \\ Jean-Pierre Després · Claude Bouchard · \\ Louis Pérusse $\cdot$ Marie-Claude Vohl
}

Received: 27 November 2007/ Accepted: 1 February 2008/Published online: 6 March 2008

(C) The Japan Society of Human Genetics and Springer 2008

\begin{abstract}
The small, dense low-density-lipoprotein (LDL) phenotype is associated with an increased atherosclerosis risk. A genome-wide scan performed on 236 nuclear families of the Quebec Family Study (QFS) revealed a quantitative trait locus (QTL) for LDL peak-particle size (LDL-PPD) on the $17 \mathrm{q} 21$ region. This region encodes the myeloperoxidase $(M P O)$ gene. MPO is able to oxidize LDL by its reactive intermediates. To test the associations between $M P O$ gene polymorphisms and LDL-PPD as well as plasma lipid levels, we performed direct sequencing of the coding regions, exon-intron splicing boundaries, and the
\end{abstract}

Electronic supplementary material The online version of this article (doi:10.1007/s10038-008-0267-1) contains supplementary material, which is available to authorized users.

G. Dolley · L. Pérusse · M.-C. Vohl ( $₫)$

CRML, CHUL Research Center, 2705 Laurier Blvd,

Quebec G1V-4G2, Canada

e-mail: Marie-Claude.Vohl@crchul.ulaval.ca

G. Dolley · B. Lamarche · M.-C. Vohl

Department of Food Science and Nutrition,

Laval University, Quebec, Canada

G. Dolley · B. Lamarche · M.-C. Vohl

Nutraceuticals and Functional Foods Institute (INAF),

Quebec, Canada

J.-P. Després

Québec Heart Institute, Quebec, Canada

J.-P. Després · L. Pérusse

Department of Social and Preventive Medicine,

Laval University, Quebec, Canada

C. Bouchard

Pennington Biomedical Research Center,

Baton Rouge, LA, USA regulatory regions on 25 subjects to identify new genetic variants. Genotyping was performed either by TaqMan or direct sequencing on 680 subjects in the QFS. LDL-PPD was measured by gradient gel electrophoresis (GGE) on nondenaturing $2-16 \%$ polyacrylamide gradient gels. $M P O$ gene sequencing revealed 16 polymorphisms. The c. $653 \mathrm{G}>\mathrm{A}$ $M P O$ polymorphism was associated with lower plasma total cholesterol, LDL cholesterol (LDL-C), and LDL apolipoprotein B (LDL-apoB) levels $(P=0.026,0.042$ and 0.014 , respectively). No significant association with a gene-dosage effect were observed for LDL-PPD. The $M P O$ gene variants are not associated with LDL-PPD and thus are unlikely to be responsible for the quantitative trait locus reported on $17 \mathrm{q} 21$. However, the c. $-653 \mathrm{G}>\mathrm{A}$ is associated with plasma LDL-C and LDL-apoB concentrations.

Keywords Genome scan $\cdot M P O$ polymorphisms

\section{Introduction}

The heterogeneity of low-density lipoprotein (LDL) particles is well known, and studies have demonstrated that a large part of the trait variability is attributable to genetic differences (Bosse et al. 2004). In this regard, we previously characterized the importance of genetic factors on LDL particle size in the Quebec Family Study (QFS) (Bosse et al. 2003b). An autosomal genome-wide scan was performed on LDL peak-particle size (PPD), a quantitative trait reflecting the size of the major LDL subclass (Bosse et al. 2003a). The strongest evidence of linkage for LDLPPD was found on chromosome 17q21 after adjustment for age, body mass index (BMI), and triglyceride levels [logarithm of odds $(\mathrm{LOD})=6.76]$. In this region, several positional candidates have already been identified and 
associated with LDL-PPD. Family-based association tests suggest that one particular haplotype of the apolipoprotein (apo) $\mathrm{H}$, with a relative allele frequency of $20.9 \%$, was associated with increased LDL-PPD trait values (Bosse et al. 2005), whereas carriers of the c.29C (c.29A > C) allele of the phosphatidylcholine transfer protein (PCTP) gene polymorphism were characterized by larger LDL particles than A/A homozygotes (Dolley et al. 2007). Although some gene variants in positional candidates have been associated with LDL-PPD, other relevant positional candidates in the $17 \mathrm{q} 21$ region remain to be studied.

The myeloperoxidase $(M P O)$ gene is located close to maker D17S1290, under the 17q21 peak (Bosse et al. 2003a). MPO is an antimicrobial agent present in neutrophils, monocytes, and some reactive microglial macrophages (Nagra et al. 1997). MPO may contribute to atherosclerosis through its ability to oxidize LDL (Carr et al. 2000), including apoE (Jolivalt et al. 1996), causing aggregation of particles that enhances uptake through macrophage scavenger receptors (Podrez et al. 2000). MPO levels in circulating leukocytes and serum are higher in individuals with coronary artery disease (CAD) (Baldus et al. 2003).

Atherosclerosis is a chronic inflammatory disease characterized by oxidative activity of phagocytic cells in the vessel wall and by the modification of LDL to an atherogenic, oxidized state. The increased atherogenicity of the small, dense LDL has been attributed to greater propensity for transport into the subendothelial space, increased binding to arterial proteoglycans, and susceptibility to oxidative modifications (Berneis and Krauss 2002). Thus, we hypothesize that MPO is etiologically linked to small, dense LDL alterations and that polymorphisms in this gene affect LDL particle size and plasma lipid levels. We also hypothesize that polymorphisms in the peroxisome proliferator-activated receptor $\gamma(P P A R G)$ gene, such as the P12A (Yen et al. 1997), exacerbate the effects of $M P O$ gene polymorphisms on LDL characteristics. This is based on the fact that PPARG ligands have been shown to regulate $M P O$ gene expression (Kumar et al. 2004). Thus, the objectives of our study were first to identify $M P O$ gene sequence variations and to test the associations between these $M P O$ gene polymorphisms and LDL features. Finally, the gene-gene interaction effects between $M P O$ and PPARG genes on LDL features were examined.

\section{Materials and methods}

\section{Subjects}

Subjects were participants of the QFS. Details of recruitment procedures have been published elsewhere
(Bouchard 1996). This cohort represents a mixture of random sampling and ascertainment through obese $\left(\mathrm{BMI}>32 \mathrm{~kg} / \mathrm{m}^{2}\right.$ ) probands. A total of 680 subjects from 236 nuclear families were considered. The study was approved by the Laval University Medical Ethics Committee, and all subjects provided written informed consent.

LDL peak-particle diameter (LDL-PPD) characterization

LDL-PPD was measured on 680 subjects by gradient gel electrophoresis (GGE) from plasma obtained after a 12-h fast. Details of the technique have been previously reported (St Pierre et al. 2001). Briefly, the whole plasma was loaded on nondenaturing $2-16 \%$ polyacrylamide gradient gel. A 15 -min prerun at $75 \mathrm{~V}$ preceded electrophoresis of the plasma samples at $150 \mathrm{~V}$ for $3 \mathrm{~h}$. Gels were stained for $1 \mathrm{~h}$ with Sudan black and stored until analysis by the Imagemaster 1-D Prime computer software (Amersham Pharmacia Biotech). LDL size forming the bands was determined on the basis of a calibration curve constructed from plasma standards. Based on GGE, a continuous variable was defined as LDL-PPD, reflecting the size of the major LDL subclass in an individual subject.

\section{Metabolic measurements}

Blood samples were obtained from an antecubital vein in the morning after a 12-h overnight fast. The plasma was separated immediately after blood collection by centrifugation at $3,000 \mathrm{rpm}(850 \mathrm{~g})$ for $10 \mathrm{~min}$ for the measurement of plasma lipoprotein/lipid levels. Cholesterol (Allain et al. 1974) and triglyceride (Fossati and Prencipe 1982) concentrations were determined enzymatically using a Technicon RA-500 automated analyzer (Bayer, Tarrytown, NY, USA). High-density-lipoprotein (HDL) fraction was obtained after precipitation of LDL in the infranatant $(>1.006 \mathrm{~g} / \mathrm{ml})$ with heparin and magnesium chloride $\left(\mathrm{MnCl}_{2}\right)$ (Burstein and Samaille 1960). The cholesterol content of the infranatant fraction was measured before and after the precipitation step for the measurement of HDL cholesterol (HDL-C) and for the calculation of LDL cholesterol (LDL-C). The apolipoprotein measurements were performed with the rocket immunoelectrophoretic method (Laurell 1966). LDL-apoB concentrations were measured in the infranatant $(d>$ $1.006 \mathrm{~g} / \mathrm{ml}$ ) obtained after separation of very-low-density lipoprotein from the plasma by ultracentrifugation. The measurements were calibrated with reference standards obtained from the Center for Disease Control and Prevention (Atlanta, GA, USA). 
Sequencing and genotyping

Direct sequencing of coding regions, exon-intron splicing boundaries, and regulatory regions was used to identify new genetic variants of the MPO gene. All sequencing of exons and exon-intron splicing boundaries were performed with specific primers derived from the $5^{\prime}$ and $3^{\prime}$ ends of intronic sequences. Primers were designed using the Primer 3.0 software available on the Whitehead Institute/MIT Centre for Genome Research server (http://www.genome. wi.mit.edu/cgi-bin/primer/primer3.cgi). Primers and cycling conditions are presented in the supplementary Table. After polymerase chain reaction (PCR) amplification, products were purified (Multiscreen, Millipore) and sequencing was performed using BigDye Terminator (version 2.0) and analyzed on ABI 3730XL sequencers (Applied BioSystems, Foster City, CA, USA). Sequences were then assembled and analyzed using Staden pre-GAP4 and GAP4 programs (Bonfield et al. 1995). Sequence screening was performed on DNA from 25 unrelated subjects from the QFS cohort having LDL-PPD at each extreme of the distribution ( $254 \AA<$ LDL-PPD $>276 \AA$ ). Genetic variants were subsequently genotyped on the whole cohort using TaqMan methodology of Applied Biosystem Company (Livak 1999). In the case of interspersed repeats or low-complexity DNA sequences, genetic variants were genotyped by direct sequencing, as described above. The $P P A R \gamma_{2}$ P12A variant is caused by a $\mathrm{C} \rightarrow \mathrm{G}$ substitution at nucleotide 34 producing a BstU-I restriction site. Genotypes were obtained by digestion of PCR products, as described in details elsewhere (Yen et al. 1997).

\section{Statistical analyses}

The independent effect of $M P O$ polymorphisms was tested by analysis of covariance comparing mean phenotypic values across the three $M P O$ genotypes, using the MIXED procedure implemented in SAS (version 9.1), which takes the nonindependence of family members into account. This procedure is used when the experimental units (in this case subjects) can be grouped into clusters (family) and the data from a common cluster are possibly correlated. For metabolic parameters, age, gender, and BMI were included as covariates in predicting models. In specific analyses, LDLPPD values were further adjusted for the effect of fasting plasma triglyceride levels. However, mean values presented in the tables are for nonadjusted phenotypes. To test for interaction between polymorphisms of the $M P O$ and $P P A R \gamma_{2}$ genes, a dummy variable was created to divide the subjects into six groups based on their genotypes ( $P P A R \gamma_{2}$ $\mathrm{P} 12 \mathrm{~A}$ and $M P O$ c. $-653 \mathrm{G}>\mathrm{A})$. The effects of the $P P A R \gamma_{2}$ $\mathrm{P} 12 \mathrm{~A}, \quad M P O \mathrm{c}-653 \mathrm{G}>\mathrm{A}$, and their interactions were quantified in the MIXED model by contrasting the dummy variable for the two main effects $\left(P P A R \gamma_{2} \mathrm{P} 12 \mathrm{~A}\right.$ and $M P O$ c. $-653 \mathrm{G}>\mathrm{A})$ and their interactions.

\section{Results}

A total of 16 genetic variants were identified. Only those with a minor allele frequency (MAF) greater than 0.05 are presented in Table $1(n=8)$. Hardy-Weinberg equilibrium test was performed using the Haploview software, version 4.0 (http://www.broad.mit.edu/mpg/haploview/). All genotype distributions were in Hardy-Weinberg equilibrium among genetically unrelated individuals.

In this study, we focused on SNPs with potential functional effects on gene expression or protein translation. Thus, five SNPs were retained for genotyping, two with the Taqman methodology (c.157G $>\mathrm{T}$, c.2149A $>\mathrm{G})$, the others (c.-822C $>$ A, c. $-765 \mathrm{~T}>\mathrm{C}$, and c. $-653 \mathrm{G}>\mathrm{A}$ ) by direct sequencing. The c.-653G $>$ A polymorphism, also known as $-463 \mathrm{G}>\mathrm{A}$ in the literature, as well as c.$822 \mathrm{C}>\mathrm{A}$ and c.-765T $>\mathrm{C}$, are located in the $5^{\prime}$ region and may potentially alter gene expression. The c. $157 \mathrm{G}>\mathrm{T}$ polymorphism that results from the substitution of a valine for an isoleucine (Val717Ile) is located in exon 2, whereas c. $2149 \mathrm{~A}>\mathrm{G}$ in exon 12 causes a change of a phenylalanine for a valine (Phe53Val).

To determine the pattern of LD and haplotype structure within the $M P O$ gene, we used the Tagger function of the Haploview software. Pairwise LD was measured by $r^{2}$ among the eight sequenced MPO SNPs. LD pattern is illustrated in Fig. 1. The five genotyped SNPs, selected according to their potential impact on the MPO gene activity, account for $75 \%$ of the gene variance.

Table 1 Allele frequencies of variants identified in the $M P O$ gene

\begin{tabular}{lll}
\hline Sequence variant & dbSNP rs no. & MAF \\
\hline Noncoding variants & & \\
c.-822C > A & rs2243827 & $0.28^{\mathrm{a}}$ \\
c.-765T > C & rs2243828 & $0.32^{\mathrm{a}}$ \\
c.-653G > A & rs2333227 & $0.32^{\mathrm{a}}$ \\
g.287C > T & rs2856857 & 0.26 \\
g.5237G > A & rs11575868 & 0.08 \\
g.9890A > C & rs2071409 & 0.1 \\
Coding variants & & \\
c.157G > T (Val53Phe) & rs7208693 & $0.06^{\mathrm{a}}$ \\
c.2149T > C (Ile717Val) & rs2759 & $0.12^{\mathrm{a}}$ \\
\hline
\end{tabular}

$d b S N P$ Database of Single Nucleotide Polymorphisms, MAF minor allele frequencies

a Allele frequency was calculated in the whole sample of 623 subjects

Allele frequencies of all other variants were calculated in the subsample of 25 subjects used for the sequencing 


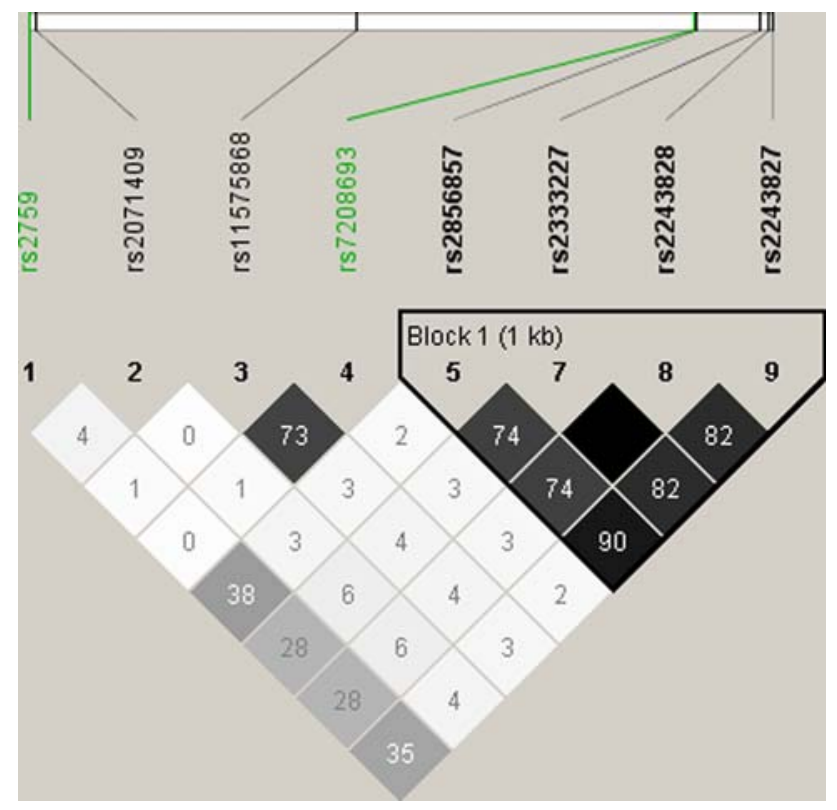

Fig. 1 The pattern of linkage disequilibrium (LD) among the $M P O$ gene polymorphisms. Pairwise LD was measured by $r^{2}$ among the eight sequenced $M P O$ single nucleotide polymorphisms (SNPs) based on the 25 subjects used for the sequencing. A $r^{2}>80$ corresponded to a strong LD

\section{$M P O$ association analyses}

Among the five SNPs, c.-653G $>$ A was significantly associated with LDL particle characteristics (Table 2). The c.-653A allele was associated with lower plasma total cholesterol $(P=0.026)$, LDL-C $(P=0.042)$, and LDLapoB $(P=0.014)$, compared with GG homozygotes. These associations were obtained when the values were adjusted for the effects of age and gender and remained unchanged when further adjustment for BMI was applied. The two other promoter SNPs presented similar association pattern but did not reach statistical significance (data not shown). This similarity within the association patterns of these three SNPs is likely to be attributable to the strong LD. Polymorphisms c.157G $>\mathrm{T}$ (Val53Phe) and c.2149A $>$ G (Ile717Val) were not associated with any of the tested phenotypes (date not shown).

For LDL-PPD, only $M P O$ c.-653G $>$ A polymorphism was statistically significant when the phenotype was adjusted for age, gender, BMI and fasting plasma triglyceride levels. Although this association was significant, the difference of mean values between the genotype groups was relatively small, with c.-653GA heterozygotes exhibiting the lowest LDL-PPD mean value (Table 2). Moreover, the maximal variance observed was inferior to $1 \AA$, which is unlikely to have significant biological impact.

Estrogens are known to modulate MPO activity in addition to increasing the amount of MPO in the plasma.
MPO activity is influenced by the c. $-653 \mathrm{G}>$ A polymorphism with the c.-653A allele creating an estrogen-receptor binding site (Reynolds et al. 2000). In this context, association analyses were performed separately for men and women (Table 3). The results indicate that women carrying the c.-653A allele had lower plasma total cholesterol $(P=0.001)$, LDL-C $(P=0.004)$ and LDL-apoB $(P=$ $0.005)$, whereas no associations were observed in men.

\section{MPO- PPARG interaction}

To evaluate the potential interaction between $M P O$ c.-653G $>$ A and PPARG $\mathrm{P} 12 \mathrm{~A}$ polymorphisms, we contrasted the six genotype groups for an interaction effect. The independent effect of each polymorphism and their interactions are summarized in Table 4. In this model, PPARG P12A was not independently associated with plasma lipid levels. In contrast, $M P O$ c.-653AA genotype was associated with lower plasma total cholesterol and LDL-apoB levels. However, the interaction between the two genes was not statistically significant for any of the tested phenotypes.

\section{Discussion}

A previous genome scan on LDL-PPD, performed on the QFS cohort, revealed several QTLs with the strongest signal on 17q (Bosse et al. 2003a). A positional candidate, $M P O$ is located under the $17 \mathrm{q} 21$ peak, near a marker (D17S1290) associated with LDL-PPD (Bosse et al. 2003a). Our study investigated the effects of $M P O$ gene polymorphisms on LDL-PPD and other plasma-lipid-related traits. Five $M P O$ SNPs were genotyped on the whole cohort. These SNPs account for about $75 \%$ of the $M P O$ gene variance. They exhibited no or only marginal association (c.-653G > A) with LDL-PPD. However, the $M P O$ c.-653A allele was associated with lower plasma total cholesterol, LDL-C and LDL-apoB levels. These results suggest that the lower plasma total cholesterol levels observed in c.-653AA homozygotes is attributable to the lower cholesterol content of LDL and to the decreased number of LDL particles (i.e., LDL-apoB).

Although no or only marginal effect was observed on LDL-PPD, the results found with LDL cholesterol support the role of MPO in atherosclerosis. Several mechanisms linking MPO to atherosclerosis have been reported so far (Nagra et al. 1997; Nauseef 2001). MPO contributes to atherosclerosis through its ability to oxidize LDL (Hazell et al. 1996), causing particle aggregation that enhances uptake through macrophage scavenger receptors (Podrez et al. 2000). MPO could also promote HDL oxidation (Bergt et al. 2004). Several studies suggested that MPO is a catalyst for 
Table 2 Association between $M P O$ c.-653G $>$ A genotype and plasma lipids

\begin{tabular}{|c|c|c|c|c|c|}
\hline c. $-653 \mathrm{G}>\mathrm{A}(n=638)$ & GG $(n=373)$ & $\mathrm{GA}(n=228)$ & $\mathrm{AA}(n=37)$ & $P$ value $^{\mathrm{a}}$ & $P$ value ${ }^{\mathrm{b}}$ \\
\hline Total cholesterol (mmol/L) & $5.00 \pm 1.2$ & $4.95 \pm 1.0$ & $4.60 \pm 1.1$ & 0.028 & 0.026 \\
\hline Triglycerides (mmol/L) & $1.53 \pm 0.8$ & $1.53 \pm 0.8$ & $1.35 \pm 0.7$ & 0.541 & 0.303 \\
\hline LDL-PPD $(\AA)$ & $263.6 \pm 4.9$ & $263.0 \pm 5.1$ & $263.9 \pm 4.2$ & 0.236 & $0.042 *$ \\
\hline LDL-C (mmol/L) & $3.07 \pm 0.9$ & $3.05 \pm 0.9$ & $2.73 \pm 0.9$ & 0.042 & 0.042 \\
\hline LDL-apoB & $0.88 \pm 0.2$ & $0.86 \pm 0.2$ & $0.78 \pm 0.2$ & 0.015 & 0.014 \\
\hline HDL-C (mmol/L) & $1.22 \pm 0.3$ & $1.21 \pm 0.3$ & $1.27 \pm 0.4$ & 0.497 & 0.270 \\
\hline
\end{tabular}

The test was performed with the MIXED procedure that takes into account relatedness among family members. Phenotypic mean values were presented without adjustments

$L D L$ low-density lipoprotein, $P P D$ peak-particle size, $a p o B$ apolipoprotein $\mathrm{B}, H D L$ high-density lipoprotein

${ }^{\text {a }}$ Variables are adjusted for age and gender

b Variables are adjusted for age, gender, and body mass index

* LDL-PPD $P$ value was further adjusted for triglyceride concentrations

Table 3 Association between $M P O$ c. $-653 \mathrm{G}>$ A genotype and plasma lipids in women

\begin{tabular}{lccccc}
\hline c.-653G $>$ A $(n=376)$ & GG $(n=22)$ & GA $(n=130)$ & AA $(n=24)$ & $P$ value ${ }^{\mathrm{a}}$ & $P$ value \\
\hline Total cholesterol $(\mathrm{mmol} / \mathrm{L})$ & $5.09 \pm 1.3$ & $4.90 \pm 1.1$ & $4.47 \pm 1.2$ & 0.001 \\
Triglycerides $(\mathrm{mmol} / \mathrm{L})$ & $1.46 \pm 0.7$ & $1.49 \pm 0.8$ & $1.22 \pm 0.5$ & 0.262 & 0.001 \\
LDL-PPD $(\AA)$ & $264.5 \pm 4.8$ & $263.7 \pm 5.0$ & $265.1 \pm 4.5$ & 0.128 & 0.052 \\
LDL-C $(\mathrm{mmol} / \mathrm{L})$ & $3.07 \pm 0.9$ & $2.94 \pm 0.9$ & $2.58 \pm 0.9$ & 0.004 & $0.037^{*}$ \\
LDL-apoB & $0.86 \pm 0.2$ & $0.83 \pm 0.2$ & $0.73 \pm 0.2$ & 0.004 & 0.004 \\
HDL-C $(\mathrm{mmol} / \mathrm{L})$ & $1.32 \pm 0.3$ & $1.30 \pm 0.3$ & $1.34 \pm 0.3$ & 0.617 & 0.227 \\
\hline
\end{tabular}

The test was performed with the MIXED procedure that takes into account relatedness among family members. Phenotypic mean values were presented without adjustments

$L D L$ low-density lipoprotein, $P P D$ peak-particle size, $a p o B$ apolipoprotein $\mathrm{B}, H D L$ high-density lipoprotein

${ }^{\text {a }}$ Variables are adjusted for age

b Variables are adjusted for age and BMI

* LDL-PPD $P$ value was further adjusted for triglyceride concentrations

Table 4 Effects of $M P O$ c.-653 G > A, PPARG P12A, and their interactions

\begin{tabular}{|c|c|c|c|c|c|c|c|c|c|}
\hline & \multicolumn{3}{|c|}{ PPARG P12 } & \multicolumn{3}{|c|}{$P P A R G 12 \mathrm{~A}$} & \multicolumn{3}{|c|}{$P$ values } \\
\hline & $\begin{array}{l}M P O \mathrm{GG} \\
(n=288)\end{array}$ & $\begin{array}{c}M P O \text { GA } \\
(n=170)\end{array}$ & $\begin{array}{l}M P O \text { AA } \\
(n=20)\end{array}$ & $\begin{array}{l}M P O \mathrm{GG} \\
(n=63)\end{array}$ & $\begin{array}{l}M P O \text { GA } \\
(n=43)\end{array}$ & $\begin{array}{l}M P O \text { AA } \\
(n=9)\end{array}$ & $M P O$ & PPARG & Interaction \\
\hline Total cholesterol (mmol/L) & $5.06 \pm 1.3$ & $5.03 \pm 1.1$ & $4.61 \pm 1.2$ & $5.01 \pm 0.9$ & $4.76 \pm 0.9$ & $4.80 \pm 1.0$ & 0.050 & 0.916 & 0.147 \\
\hline LDL-C (mmol/L) & $3.12 \pm 0.9$ & $3.11 \pm 0.9$ & $2.80 \pm 1.0$ & $3.11 \pm 0.9$ & $2.93 \pm 0.8$ & $2.93 \pm 0.8$ & 0.083 & 0.531 & 0.122 \\
\hline apoB LDL & $0.89 \pm 0.2$ & $0.87 \pm 0.2$ & $0.78 \pm 0.2$ & $0.85 \pm 0.2$ & $0.82 \pm 0.2$ & $0.75 \pm 0.2$ & 0.014 & 0.384 & 0.440 \\
\hline
\end{tabular}

The test was performed with the MIXED procedure that takes into account relatedness among family members

$P$ values were adjusted for the effects of age, gender, and body mass index

$L D L$ low-density lipoprotein, $a p o B$ apolipoprotein $\mathrm{B}$

lipid peroxidation via tyrosyl radical formation (Savenkova et al. 1994) and for lipid and lipoprotein oxidative modifications via generation of reactive nitrogen species (Zhang et al. 2002; Podrez et al. 1999). Thus, decreased MPO circulation levels caused by c.-653G $>$ A polymorphism could attenuate LDL oxidation and consequently facilitate LDL reuptake by the liver. Indeed, LDL oxidation confers alternative configuration of LDL particles and then alters their recognition by the LDL receptor in the liver (Witztum and Steinberg 1991). Ultimately, through this mechanism, MPO c. $-653 \mathrm{G}>\mathrm{A}$ could decrease the process of atherosclerosis leading to coronary artery disease. 
Individuals with MPO deficiency were shown to have a significantly reduced risk of CAD (Kutter et al. 2000), whereas high circulating levels of MPO is thought to increase oxidative damage and could lead to higher risk of CAD (Baldus et al. 2003; Grahl et al. 2007). In our study, MPO SNPs were selected for their potential impact on gene expression or protein activity. Thus, c. $157 \mathrm{G}>\mathrm{T}$ (Val53Phe) and c.2149A $>$ G (Ile717Val) located in the coding regions represent good candidates, and they correspond to amino acid changes. To determine biological impact of these SNPs on protein activity, we used PolyPhen, a specific software for predicting the impact of amino acid substitution on the structure and function of human protein (http://genetics.bwh.harvard.edu/pph/). Results indicate that both Val53Phe and Ile717Val variants are predicted to be benign and thus could unlikely modify significantly protein conformation. These results could explain the lack of association of these polymorphisms with cholesterol transport elements observed in this study. Nevertheless, previously reported results by Chevalier et al. suggested that Val53Phe enhance mRNA or precursor stability and thus increased MPO amount within the cells (Chevrier et al. 2006). In this latter study, MPO activity was measured in neutrophils of 102 subjects according to nine SNPs grouped into haplotypes. Concerning the variants located in the promoter, c.-822C $>\mathrm{A}$ and c.-765T $>\mathrm{C}$ does not appear to be located in known or putative regulatory sequence. However, they demonstrated that c.-822C $>$ A SNP was independently associated with increase MPO activity (Chevrier et al. 2006). The authors suggested that this polymorphism could enhance promoter transcriptional activity or stabilize $M P O$ mRNA, leading to an increase in enzyme activity. By contrast, $M P O$ c. $-653 \mathrm{G}>\mathrm{A}$, also described in numerous studies as $M P O-463 \mathrm{G}>\mathrm{A}$, is a well-known functional $M P O$ promoter polymorphism associated with gene expression levels (Piedrafita et al. 1996). Piedrafita et al. reported that the $M P O$ c. $-653 \mathrm{G}>\mathrm{A}$ gene polymorphism was associated with $M P O$ expression levels (Piedrafita et al. 1996). The c.-653GG genotype has been linked to higher $M P O$ mRNA and protein expression than GA/AA genotypes (Piedrafita et al. 1996). In addition, GA and AA genotypes showed protective effect for CAD, whereas homozygotes GG exhibited a higher prevalence of cardiovascular disease (Baldus et al. 2003; Grahl et al. 2007; Nikpoor et al. 2001). These observations are consistent with our findings, suggesting a protective effect of the c.-653A allele through lower plasma total cholesterol, LDL-C, and LDL-apoB levels.

The c. $-653 \mathrm{G}>\mathrm{A}$ is located within an Alu-encoded hormone response element (AluHRE) consisting of a cluster of four hexamer half sites. This cluster is recognized by various nuclear receptors (Piedrafita et al. 1996;
Vansant and Reynolds 1995): c.-653G in the first hexamer creates an SP1 site, whereas c.-653A creates a binding site for the estrogen receptor $\alpha(E R-\alpha)$. This raises the possibility that the estrogen receptor may contribute to differential regulation of $M P O$ among $\mathrm{G}$ and $\mathrm{A}$ allele carriers in men and women, as reported in numerous studies (Kumar et al. 2004; Reynolds et al. 2000; Norris et al. 1995). In this regard, we analyzed the effects of the $M P O$ c. $-653 \mathrm{G}>\mathrm{A}$ polymorphism on LDL characteristics separately in men and women. In accordance with a previous study (Makela et al. 2006), we observed a protective effect of this SNP in women (Table 3).

In contrast, it has been reported that estrogen enhances MPO activity (Jansson 1991) in addition to increasing the amount of MPO in plasma (Santanam et al. 1998). This is in agreement with studies reporting association between Alzheimer's disease risk and $M P O$ c.-653A allele in men (Reynolds et al. 2000; Leininger-Muller et al. 2003), whereas the same research group reported that the c.653G allele was more frequent in women with Alzheimer's disease (Reynolds et al. 1999). Thus, opposite effects according to $M P O$ genotypes were reported in previous studies, and this discrepancy in results could be attributable to gender-dependent (Reynolds et al. 1999) or agedependent differences (Rutgers et al. 2003) in MPO activity.

However, Kumar et al. (Kumar et al. 2004) demonstrated that gender differences in $M P O$ c. $-653 \mathrm{G}>\mathrm{A}$ polymorphism association are not caused by a direct impact of estrogen receptor binding on the $M P O$ promoter. Indeed, $P P A R G$ heterodimerizes with retinoid $\mathrm{X}$ receptor (RXR) to bind two direct $M P O$ hexamers. Estrogen receptor and PPAR $\gamma$ seem to compete for the binding to AluHRE. Thus, the ability of estrogen to block PPAR $\gamma$ effects, especially in the presence of the A allele, could explain the gender differences in the c. $653 \mathrm{G}>\mathrm{A}$ polymorphism association with disease risk. However, our results showed that no $M P O-P P A R G$ interaction was observed and only $M P O$ c. $-653 \mathrm{G}>\mathrm{A}$ was associated with plasma-cholesterol-related traits. The lack of association could be attributable to the low number of subjects upon which the present study is based. Another possible explanation may be that the c. $-653 \mathrm{~A}$ allele in the $M P O$ promoter blocks PPAR $\gamma$ binding through competitive binding by the estrogen receptor.

In conclusion, among the $M P O$ gene polymorphisms that could potentially alter gene expression or protein activity, only c.-653G $>$ A showed independent association with plasma total cholesterol, LDL-C, and LDL-apoB levels. However, no clear association was found between $M P O$ polymorphisms and LDL-PPD. Thus, MPO is unlikely to be the gene responsible for the QTL previously observed in the $17 \mathrm{q} 21$ region in the QFS cohort. 
Acknowledgments This study was supported by the Canadian Institutes of Health Research (MOP-44074). The authors express their gratitude to the subjects for their excellent collaboration and to the staff of the Physical Activity Sciences Laboratory for their contribution to the study. We also express our gratitude to A. Houde for his help in collecting genotypes. G. Dolley is supported by a studentship of the Laval University Foundation. B. Lamarche is a recipient of the Canada Research Chair in Nutrition, Functional Foods and Cardiovascular Health. JP Després is chair professor of human nutrition, lipidology and prevention of cardiovascular disease supported by Provigo and Pfizer Canada. C. Bouchard is partially funded by the George A. Bray Chair in Nutrition.

\section{References}

Allain CC, Poon LS, Chan CS, Richmond W, Fu PC (1974) Enzymatic determination of total serum cholesterol. Clin Chem 20:470-475

Baldus S, Heeschen C, Meinertz T, Zeiher AM, Eiserich JP, Munzel T, Simoons ML, Hamm CW (2003) Myeloperoxidase serum levels predict risk in patients with acute coronary syndromes. Circulation 108:1440-1445

Bergt C, Pennathur S, Fu X, Byun J, O’Brien K, McDonald TO, Singh P, Anantharamaiah GM, Chait A, Brunzell J, Geary RL, Oram JF, Heinecke JW (2004) The myeloperoxidase product hypochlorous acid oxidizes HDL in the human artery wall and impairs ABCA1-dependent cholesterol transport. Proc Natl Acad Sci USA 101:13032-13037

Berneis KK, Krauss RM (2002) Metabolic origins and clinical significance of LDL heterogeneity. J Lipid Res 43:1363-1379

Bonfield JK, Smith K, Staden R (1995) A new DNA sequence assembly program. Nucleic Acids Res 23:4992-4999

Bosse Y, Perusse L, Despres JP, Lamarche B, Chagnon YC, Rice T, Rao DC, Bouchard C, Vohl MC (2003a) Evidence for a major quantitative trait locus on chromosome $17 \mathrm{q} 21$ affecting lowdensity lipoprotein peak particle diameter. Circulation 107: 2361-2368

Bosse Y, Vohl MC, Despres JP, Lamarche B, Rice T, Rao DC, Bouchard C, Perusse L (2003b) Heritability of LDL peak particle diameter in the Quebec Family Study. Genet Epidemiol 25: 375-381

Bosse Y, Perusse L, Vohl MC (2004) Genetics of LDL particle heterogeneity: from genetic epidemiology to DNA-based variations. J Lipid Res 45:1008-1026

Bosse Y, Feitosa MF, Despres JP, Lamarche B, Rice T, Rao DC, Bouchard C, Perusse L, Vohl MC (2005) Detection of a major gene effect for LDL peak particle diameter and association with apolipoprotein $\mathrm{H}$ gene haplotype. Atherosclerosis 182:231-239

Bouchard C (1996) Genetic epidemiology, association, and sib-pair linkage: results from the Québec family study. In: Bray GA, Ryan DH (eds) Molecular and genetic aspects of obesity. Louisiana State University Press, Baton Rouge, pp 470-481

Burstein M, Samaille J (1960) On a rapid determination of the cholesterol bound to the serum alpha- and beta-lipoproteins. Clin Chim Acta 5:609

Carr AC, McCall MR, Frei B (2000) Oxidation of LDL by myeloperoxidase and reactive nitrogen species: reaction pathways and antioxidant protection. Arterioscler Thromb Vasc Biol 20:1716-1723

Chevrier I, Tregouet DA, Massonnet-Castel S, Beaune P, Loriot MA (2006) Myeloperoxidase genetic polymorphisms modulate human neutrophil enzyme activity: genetic determinants for atherosclerosis? Atherosclerosis 188:150-154
Dolley G, Berthier MT, Lamarche B, Despres JP, Bouchard C, Perusse L, Vohl MC (2007) Influences of the phosphatidylcholine transfer protein gene variants on the LDL peak particle size. Atherosclerosis 195:297-302

Fossati P, Prencipe L (1982) Serum triglycerides determined colorimetrically with an enzyme that produces hydrogen peroxide. Clin Chem 28:2077-2080

Grahl DA, Axelsson J, Nordfors L, Heimburger O, Barany P, Qureshi AR, Kato S, Watanabe M, Suliman M, Riella MC, Lindholm B, Stenvinkel P, Pecoits-Filho R (2007) Associations between the CYBA 242C/T and the MPO -463G/A polymorphisms, oxidative stress and cardiovascular disease in chronic kidney disease patients. Blood Purif 25:210-218

Hazell LJ, Arnold L, Flowers D, Waeg G, Malle E, Stocker R (1996) Presence of hypochlorite-modified proteins in human atherosclerotic lesions. J Clin Invest 97:1535-1544

Jansson G (1991) Oestrogen-induced enhancement of myeloperoxidase activity in human polymorphonuclear leukocytes-a possible cause of oxidative stress in inflammatory cells. Free Radic Res Commun 14:195-208

Jolivalt C, Leininger-Muller B, Drozdz R, Naskalski JW, Siest G (1996) Apolipoprotein $\mathrm{E}$ is highly susceptible to oxidation by myeloperoxidase, an enzyme present in the brain. Neurosci Lett 210:61-64

Kumar AP, Piedrafita FJ, Reynolds WF (2004) Peroxisome proliferator-activated receptor gamma ligands regulate myeloperoxidase expression in macrophages by an estrogen-dependent mechanism involving the $-463 \mathrm{GA}$ promoter polymorphism. J Biol Chem 279:8300-8315

Kutter D, Devaquet P, Vanderstocken G, Paulus JM, Marchal V, Gothot A (2000) Consequences of total and subtotal myeloperoxidase deficiency: risk or benefit? Acta Haematol 104:10-15

Laurell CB (1966) Quantitative estimation of proteins by electrophoresis in agarose gel containing antibodies. Anal Biochem 15: $45-52$

Leininger-Muller B, Hoy A, Herbeth B, Pfister M, Serot JM, StavljenicRukavina M, Massana L, Passmore P, Siest G, Visvikis S (2003) Myeloperoxidase G-463A polymorphism and Alzheimer's disease in the ApoEurope study. Neurosci Lett 349:95-98

Livak KJ (1999) Allelic discrimination using fluorogenic probes and the 5' nuclease assay. Genet Anal 14:143-149

Makela R, Dastidar P, Jokela H, Jaakkola O, Saarela M, Punnonen R, Lehtimaki T (2006) Relation of myeloperoxidase promoter polymorphism and long-term hormone replacement therapy to oxidized low-density lipoprotein autoantibodies in postmenopausal women. Scand J Clin Lab Invest 66:371-383

Nagra RM, Becher B, Tourtellotte WW, Antel JP, Gold D, Paladino T, Smith RA, Nelson JR, Reynolds WF (1997) Immunohistochemical and genetic evidence of myeloperoxidase involvement in multiple sclerosis. J Neuroimmunol 78:97-107

Nauseef WM (2001) Contributions of myeloperoxidase to proinflammatory events: more than an antimicrobial system. Int J Hematol 74:125-133

Nikpoor B, Turecki G, Fournier C, Theroux P, Rouleau GA (2001) A functional myeloperoxidase polymorphic variant is associated with coronary artery disease in French-Canadians. Am Heart $\mathbf{J}$ 142:336-339

Norris J, Fan D, Aleman C, Marks JR, Futreal PA, Wiseman RW, Iglehart JD, Deininger PL, McDonnell DP (1995) Identification of a new subclass of Alu DNA repeats which can function as estrogen receptor-dependent transcriptional enhancers. J Biol Chem 270:22777-22782

Piedrafita FJ, Molander RB, Vansant G, Orlova EA, Pfahl M, Reynolds WF (1996) An Alu element in the myeloperoxidase promoter contains a composite SP1-thyroid hormone-retinoic acid response element. J Biol Chem 271:14412-14420 
Podrez EA, Schmitt D, Hoff HF, Hazen SL (1999) Myeloperoxidasegenerated reactive nitrogen species convert LDL into an atherogenic form in vitro. J Clin Invest 103:1547-1560

Podrez EA, Febbraio M, Sheibani N, Schmitt D, Silverstein RL, Hajjar DP, Cohen PA, Frazier WA, Hoff HF, Hazen SL (2000) Macrophage scavenger receptor CD36 is the major receptor for LDL modified by monocyte-generated reactive nitrogen species. J Clin Invest 105:1095-1108

Reynolds WF, Rhees J, Maciejewski D, Paladino T, Sieburg H, Maki RA, Masliah E (1999) Myeloperoxidase polymorphism is associated with gender specific risk for Alzheimer's disease. Exp Neurol 155:31-41

Reynolds WF, Hiltunen M, Pirskanen M, Mannermaa A, Helisalmi S, Lehtovirta M, Alafuzoff I, Soininen H (2000) MPO and APOEepsilon4 polymorphisms interact to increase risk for AD in Finnish males. Neurology 55:1284-1290

Rutgers A, Heeringa P, Giesen JE, Theunissen RT, Jacobs H, Tervaert JW (2003) Neutrophil myeloperoxidase activity and the influence of two single-nucleotide promoter polymorphisms. Br J Haematol 123:536-538

Santanam N, Shern-Brewer R, McClatchey R, Castellano PZ, Murphy AA, Voelkel S, Parthasarathy S (1998) Estradiol as an antioxidant: incompatible with its physiological concentrations and function. J Lipid Res 39:2111-2118
Savenkova ML, Mueller DM, Heinecke JW (1994) Tyrosyl radical generated by myeloperoxidase is a physiological catalyst for the initiation of lipid peroxidation in low density lipoprotein. J Biol Chem 269:20394-20400

St Pierre AC, Ruel IL, Cantin B, Dagenais GR, Bernard PM, Despres JP, Lamarche B (2001) Comparison of various electrophoretic characteristics of LDL particles and their relationship to the risk of ischemic heart disease. Circulation 104:22952299

Vansant G, Reynolds WF (1995) The consensus sequence of a major Alu subfamily contains a functional retinoic acid response element. Proc Natl Acad Sci USA 92:8229-8233

Witztum JL, Steinberg D (1991) Role of oxidized low density lipoprotein in atherogenesis. J Clin Invest 88:1785-1792

Yen CJ, Beamer BA, Negri C, Silver K, Brown KA, Yarnall DP, Burns DK, Roth J, Shuldiner AR (1997) Molecular scanning of the human peroxisome proliferator activated receptor gamma (hPPAR gamma) gene in diabetic Caucasians: identification of a Pro12Ala PPAR gamma 2 missense mutation. Biochem Biophys Res Commun 241:270-274

Zhang R, Brennan ML, Shen Z, MacPherson JC, Schmitt D, Molenda CE, Hazen SL (2002) Myeloperoxidase functions as a major enzymatic catalyst for initiation of lipid peroxidation at sites of inflammation. J Biol Chem 277:46116-46122 